\title{
T⿱乛龰UDelft
}

The Key to Prediction in Ungauged Basins

Can we predict runoff without ground stations?

Hubert H. G. Savenije

Dept. of Water Management,
Delft University of Technology, Netherlands

What is required?

1. A model structure reflecting dominant processes in the landscape

Independent estimation of key parameters (root zone storage capacity)

3. Climatic drivers observed from space (E and $P$ ) 4. Information to constrain remaining parameters

\section{What is available?}

DEM at $30 \mathrm{~m}$ resolution

P (CHIRPS $0.05^{\circ}, \mathrm{CRU} 0.5^{\circ}$ ) and E (SSEBop 0.01\%, MOD16 $\left.0.05^{\circ}\right)$, ERA-I $\left(0.5^{\circ}\right)$

W: Total Water Equivalent from GRACE at $1-2^{\circ}$ resolution

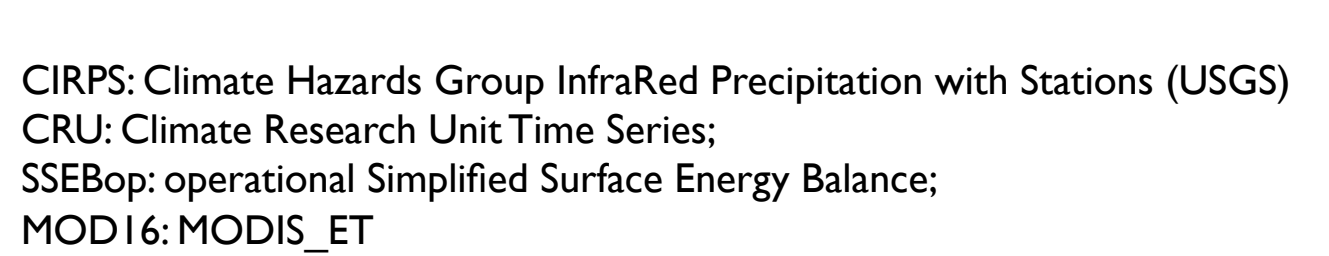

\section{Model Structure}

From DEM

HAND (height above the nearest drain)

Slope

Elevation (for tree line and snow limit)

Aspect (different ecosystem)

5. Low HAND: Wetland
High slope: Hillslope

HAND map

High HAND, low slope: Terrace and Plateau

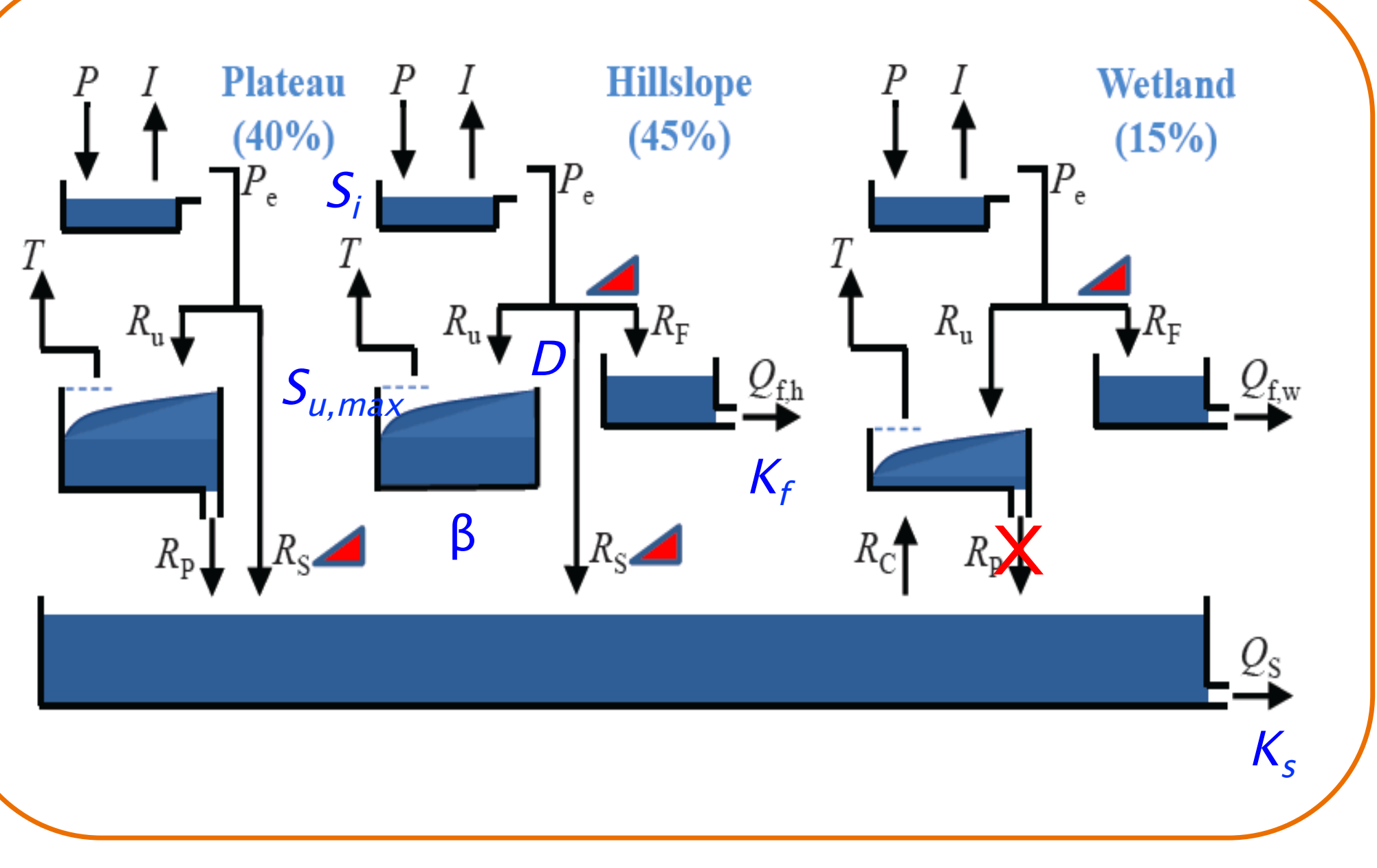

Key parameters:

$S_{u, \max }$ : root zone storage capacity

$\beta$ : shape of the VIC-type threshold

$D$ : splitter for recharge

$K_{s}:$ recession of groundwater flow

$f_{\text {: }}$ : recession of fast flow

$S_{i}$ : interception capacity

\section{Flow diagram for PUB}

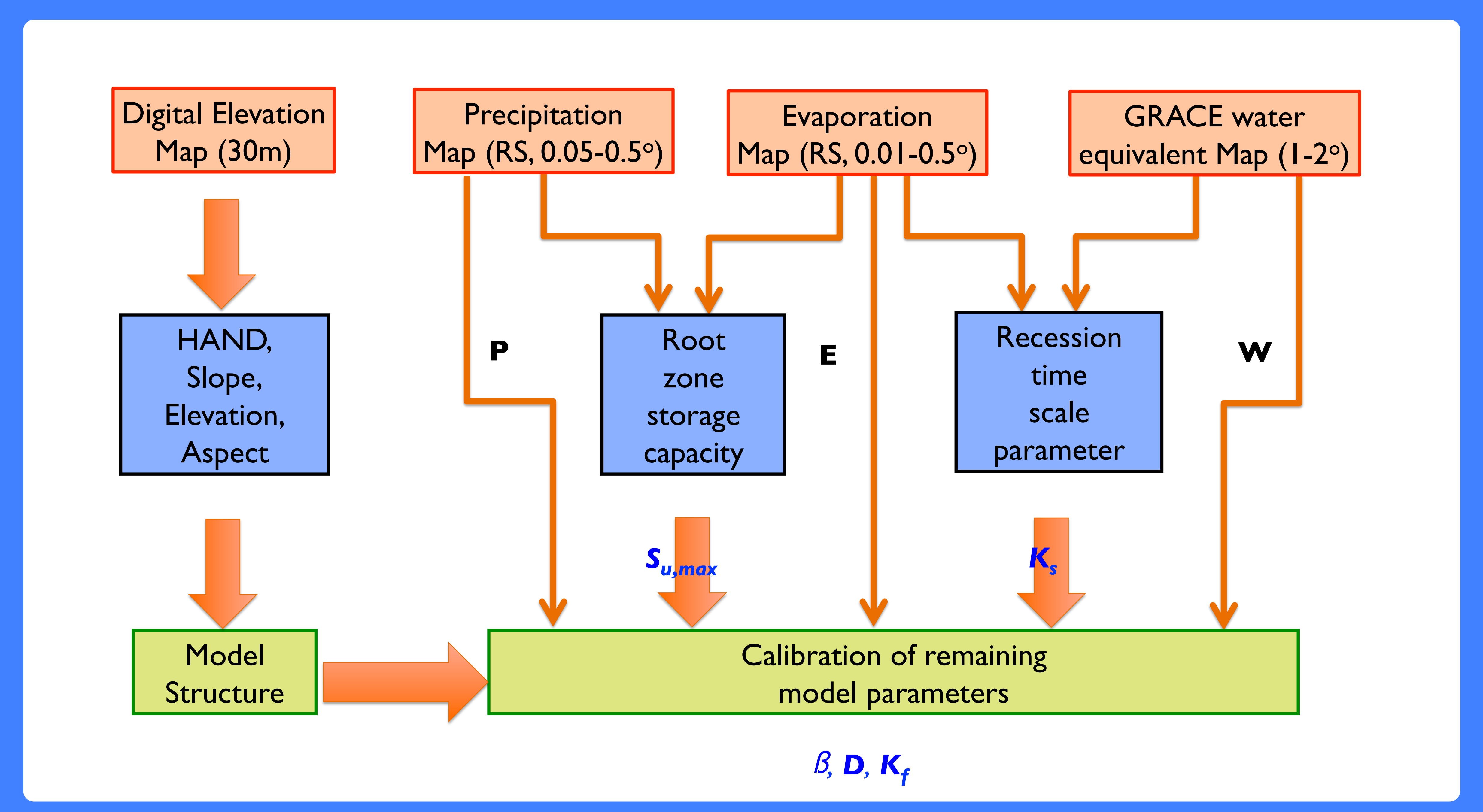

$$
\frac{\mathrm{d} W}{\mathrm{~d} t}=\frac{\mathrm{d} S_{g}}{\mathrm{~d} t}+\frac{\mathrm{d} S_{u}}{\mathrm{~d} t}+\frac{\mathrm{d} S_{s}}{\mathrm{~d} t}=P-E-Q
$$

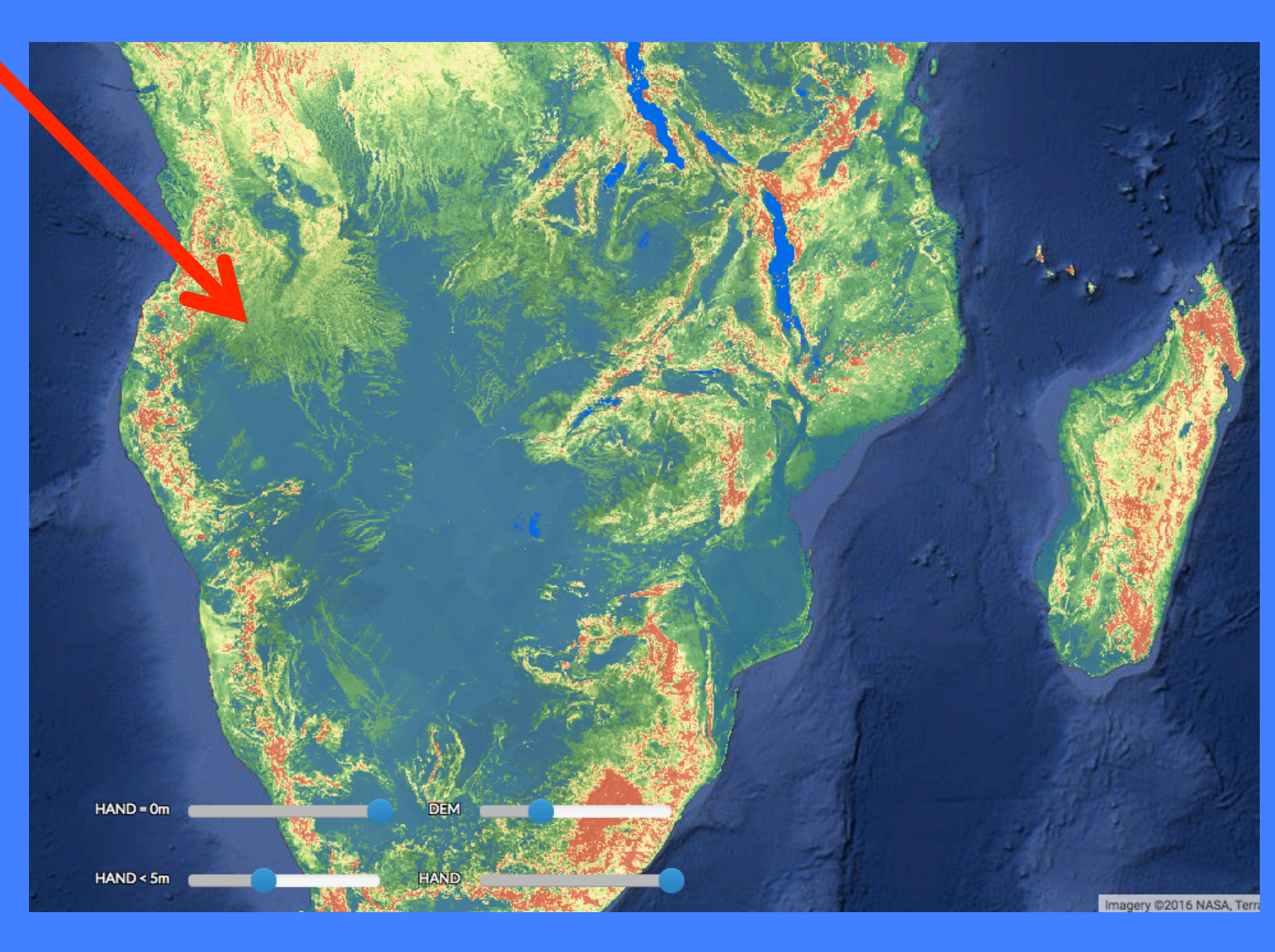

Acknowledgements

This work builds on extensive contributions of my (former) students and colleagues: Shervan Gharari, Hongkai Gao, Tanja Euser, Laurène Bang-Erlandsson

Remko Nijzink, Markus Hrachowitz, Fabrizio Fenicia, Wim Bastianssen

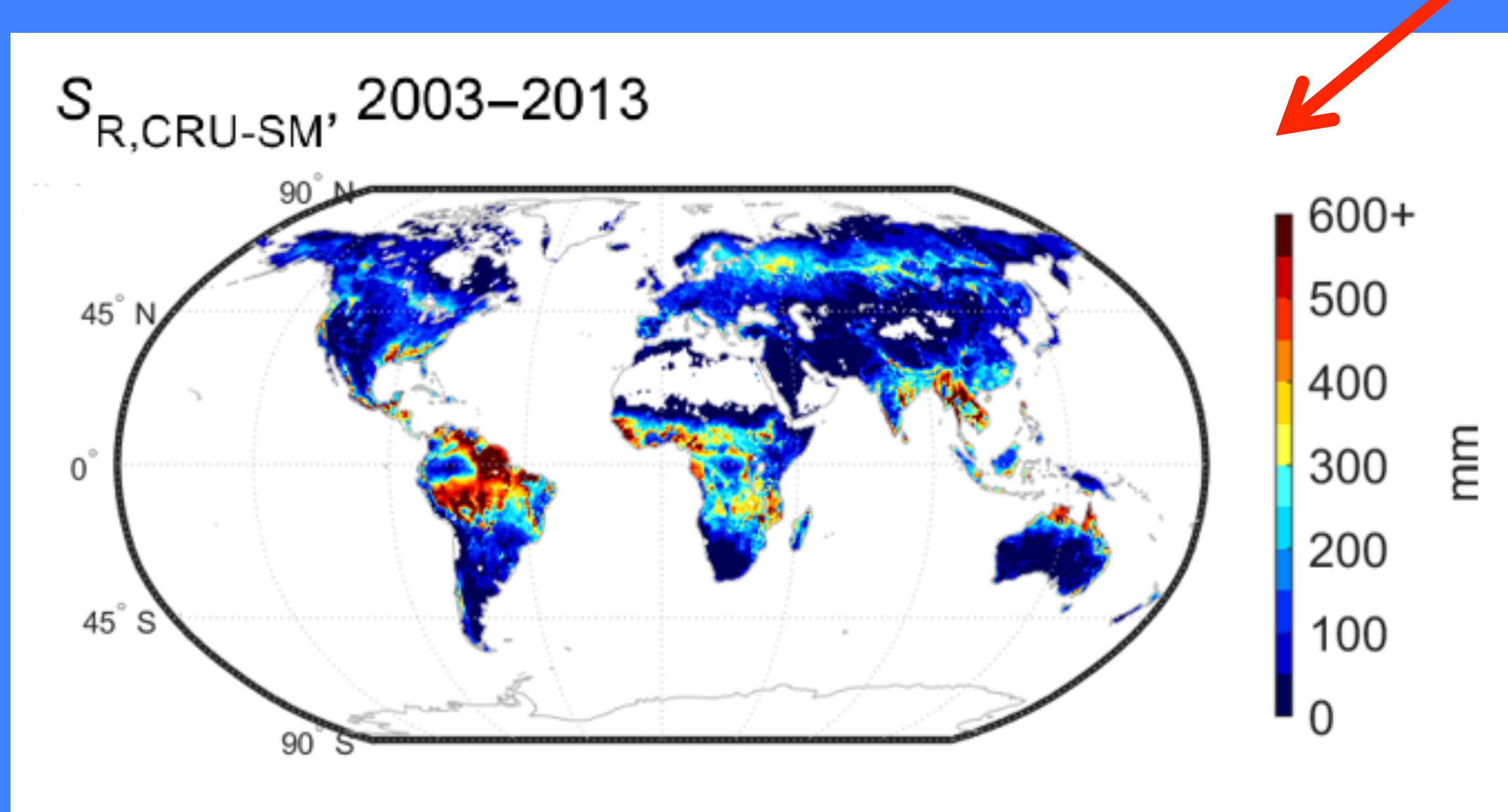

References

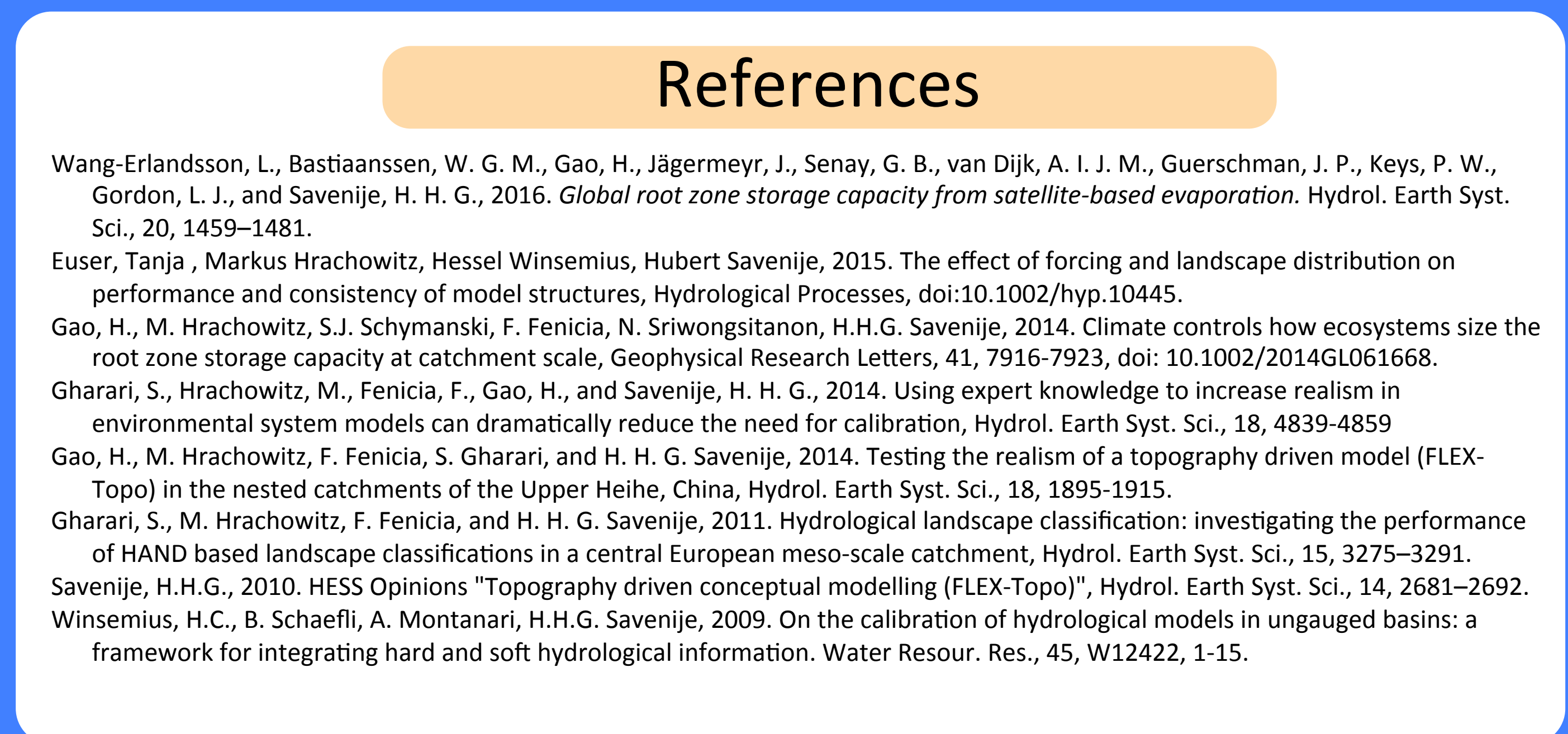

Recession Coefficient

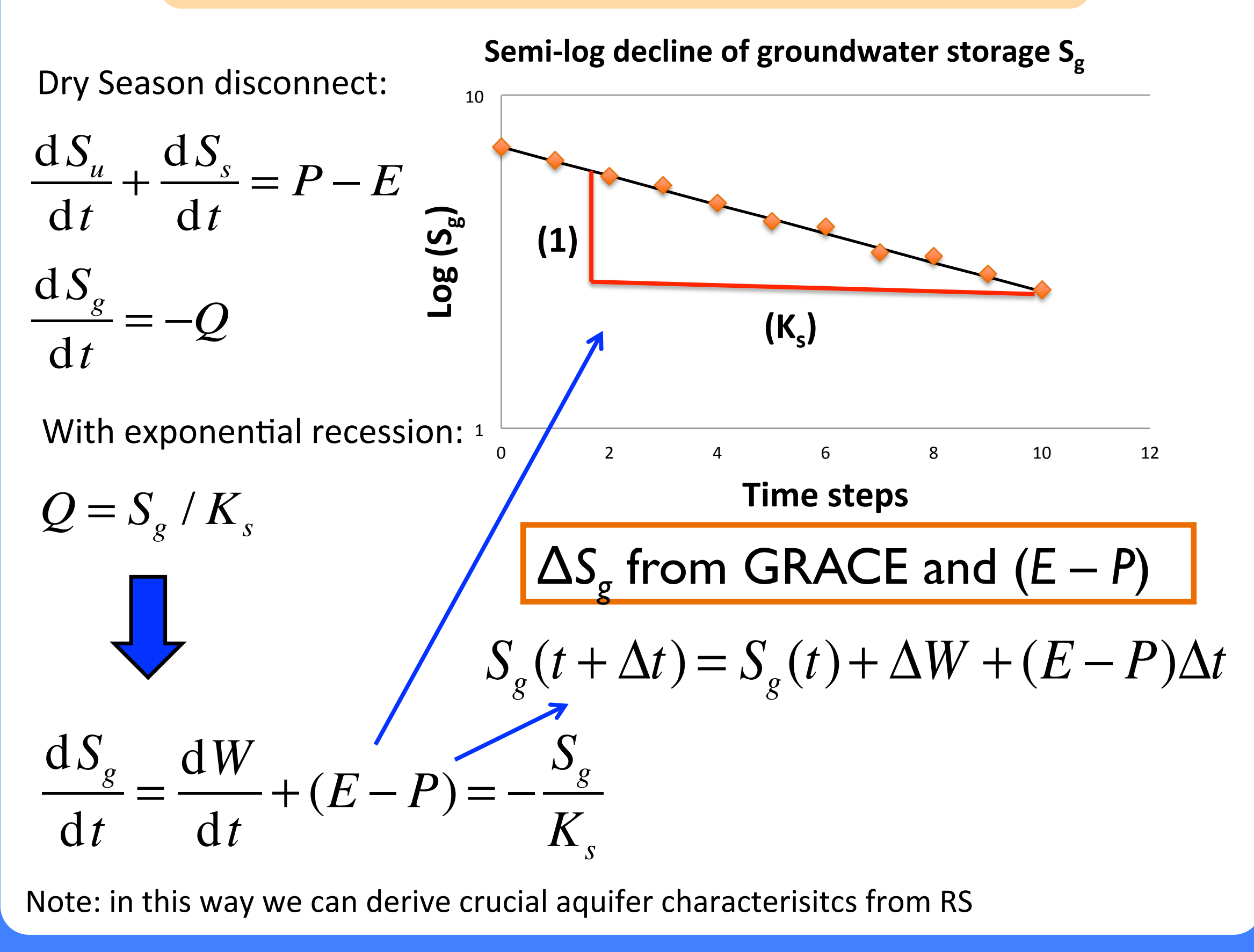

Note: in this way we can derive crucial aquifer characterisitcs from RS

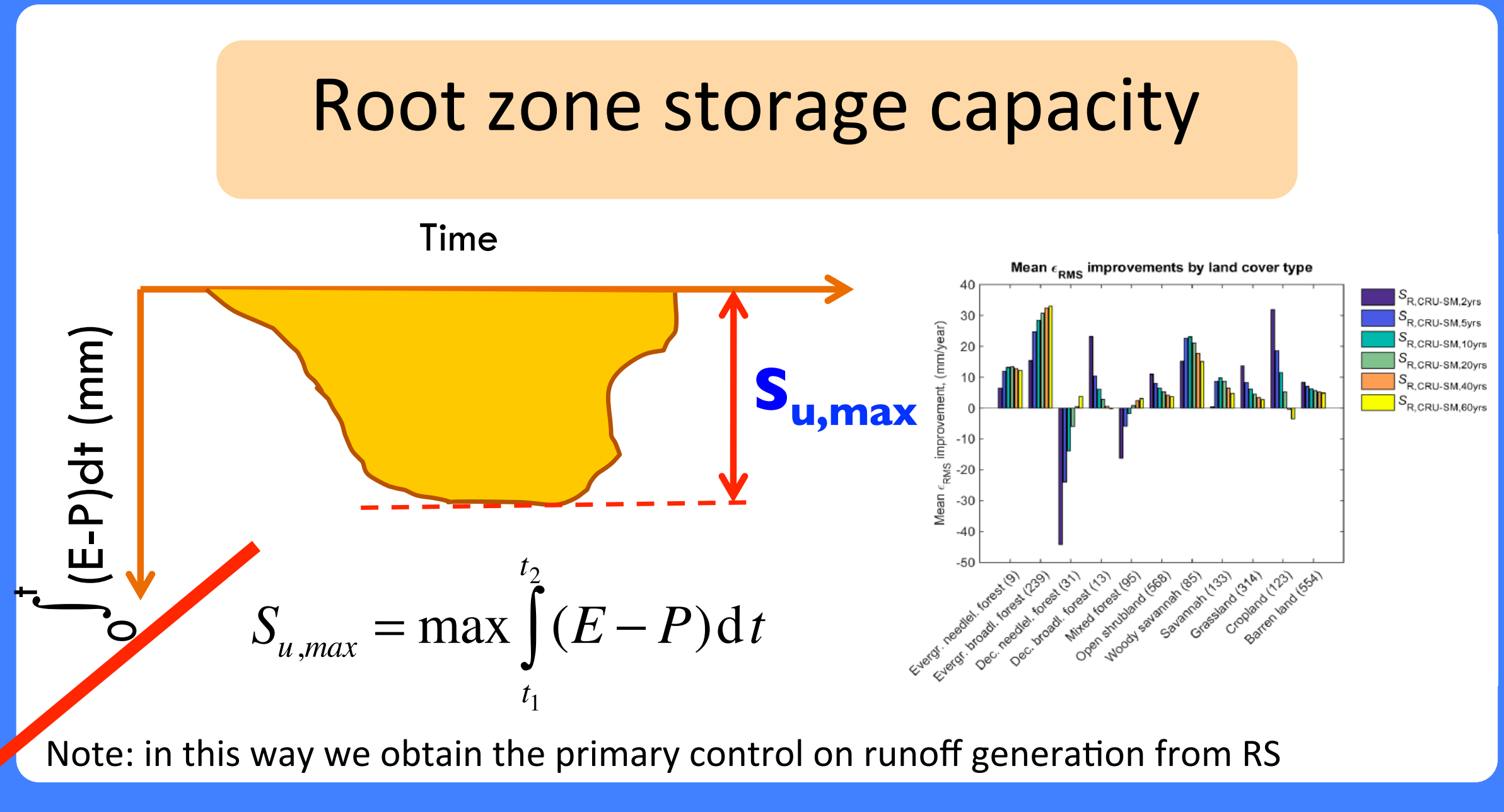

Calibrating remaining parameters

Using time series of $P, E$ and $W$, the remaining parameters can be further constrained. Key parameters to be constrained are: parameter of the root zone (VIC-like)

preferential recharge and fast runoff . the fast recession parameter $K_{f}$

Use comparative constraints bet

landscapes, e.g. $S_{u, \max }$ and

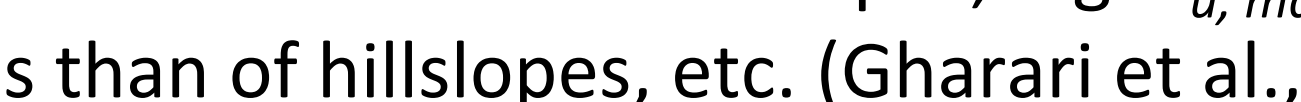
2014)

\section{Conclusions}

The method is, in principle, scale independent up to the Representative Elementary Area

It is possible to predict runoff in ungauged areas for the entre the is provided we interpret the landscape for its dominant

mechanisms

balance and main characteristics are obtainable

4. As more detailed information becomes available the method will become more accurate 